\title{
Participation of the cysteinyl leukotrienes in the acute bronchoconstrictor response to inhaled platelet activating factor in man
}

\author{
D A Spencer, J M Evans, S E Green, P J Piper, J F Costello
}

\begin{abstract}
To determine whether the effects of platelet activating factor on the airways may be due to the production of leukotrienes we studied the effects of pretreatment with the selective cysteinyl leukotriene antagonist SK\&F 104353- $Z_{2}$ on the airway and cellular responses to inhaled platelet activating factor. Eight healthy men were studied in a randomised, double blind placebo controlled crossover study. A single dose of platelet activating factor that caused a fall of at least $35 \%$ in specific airways conductance (sGaw) was determined initially for each subject. Challenge with this dose of platelet activating factor was then carried out on two further occasions after pretreatment with a single nebulised dose of SK\&F 104353-Z $Z_{2}$ or placebo. The $\%$ reductions in specific airways conductance and of partial flow at $30 \%$ of vital capacity $\left(\mathbf{P} \max _{30}\right)$ were less after SK\&F 104353-Z, than after placebo (22 versus 34 for sGaw, 19 versus 31 for PV $\left.\max _{30}\right)$. The mean (95\% confidence limits (CL)) differences in the maximum $\%$ fall from control values for SK\&F $104353-Z_{2}$ and placebo were $-12 \cdot 6$ $(-23.8,-1.4)$ for sGaw and -12.5 , $(-20 \cdot 8-4 \cdot 2)$ for $P V \max _{30}$. The mean $\%$ fall in neutrophil count was similar after SK\&F $104353-Z_{2}(46 \%)$ and after placebo $(50 \%)(95 \% \mathrm{CL}$ of difference $13 \cdot 6,6 \cdot 6)$. Bronchial responsiveness to methacholine did not increase above baseline values in any subject when measured two weeks after challenge by platelet activating factor. This study suggests that leukotrienes play a part in the response to platelet activating factor in man.
\end{abstract}

Department of Thoracic Medicine, King's College School of Medicine and Dentistry, London SE5 9PJ

D A Spencer

J M Evans

$S$ E Green

J F Costello

Department of

Pharmacology, Royal

College of Surgeons,

London WC2A 3PN

P J Piper

Reprint requests to:

Dr Spencer, Birmingham

Childrens Hospital

Birmingham B16 8ET

Accepted 15 March 1991

Asthma has an important inflammatory component, in which numerous mediators may play a part. ${ }^{1}$ Complex interactions between mediators have been reported, ${ }^{2-5}$ and these, by amplifying the effects of individual mediators, could cause bronchial responsiveness to be increased. ${ }^{1}$

The cysteinyl leukotrienes and platelet activating factor (PAF) cause acute bronchoconstriction and increased bronchial responsiveness in various animals, and may be important mediators in asthma. ${ }^{6-8}$ Inhaled PAF causes acute bronchoconstriction in flushing, and a desire to cough. ${ }^{9}{ }^{10}$ Leukotriene $\mathrm{D}_{4}$ is one of the most potent naturally occurring bronchoconstrictors known, being up to 6000 times more potent than histamine. ${ }^{11} \mathrm{~A}$ prolonged increase in bronchial responsiveness has been reported to follow inhalation of PAF in normal subjects ${ }^{9}$ and of leukotriene $E_{4}$ in asthmatic subjects. ${ }^{12}$

The effects of PAF may depend on secondary leukotriene production. Human eosinophils produce large amounts of leukotriene $\mathrm{C}_{4}$ when stimulated by PAF, ${ }^{13}$ and PAF induced mucus production in human airways is reduced by a 5 -lipoxygenase inhibitor in vitro. ${ }^{14}$ The administration of PAF results in leukotriene formation ${ }^{15}$ or biological effects that are reduced by 5-lipoxygenase inhibitors and leukotriene receptor antagonists in some animal models, ${ }^{16-18}$ though these findings have not been confirmed in other studies. ${ }^{19}{ }^{20}$ Interpretation of the animal work is made difficult by considerable interspecies variation in the effects of lipid mediators, and by the lack of potency and selectivity of the earlier leukotriene antagonists and enzyme inhibitors.

SK\&F 104353-Z $Z_{2}$ (2-(S)-hydroxy-3(R)-[(2carboxyethyl)thio]-3-[2-(8-phenyloctyl)phenyl]-propanoic acid), a structural analogue of leukotriene $\mathrm{D}_{4}$, is a potent and selective antagonist of the cysteinyl leukotrienes. ${ }^{21}$ It inhibits the bronchoconstriction induced by leukotriene $\mathrm{D}_{4}$, but not histamine, in $\operatorname{man}^{22}$ and is a potent antagonist of $\mathrm{LTC}_{4}$ and $\mathrm{LTE}_{4}$ induced contraction of human bronchus in vitro. ${ }^{23}$ It has no effect on PAF or histamine induced contraction of guinea pig trachea, or phosphodiesterase activity in canine tracheal smooth muscle. ${ }^{23}$ We have studied the effects of inhaled SK\&F $104353-Z_{2}$ on the responses to inhaled PAF in man. man, a transient fall in circulating neutrophils,

\section{Methods}

SUBJECTS

Eight non-smoking healthy men (aged 22-32 years) gave signed informed consent to participate in the study, which was approved by the hospital ethics committee. No subject gave a history of asthma and all had bronchial responsiveness to methacholine above $8 \mathrm{mg} /$ ml. ${ }^{24}$ Two subjects had positive skinprick test responses to common allergens; one, with a history of mild hay fever, was studied outside the pollen season. No subject was taking any medication and beverages containing caffeine were not consumed for at least six hours before any challenge. The results of physical 
examination, chest radiography, electrocardiography, and routine haematological and biochemical screening were all within normal limits.

\section{MATERIALS}

Methacholine hydrochloride (Sigma Chemical Company, St Louis, Missouri) was made up by the hospital pharmacy in doubling concentrations from 0.5 to $64 \mathrm{mg} / \mathrm{ml}$. C-18 PAF (Bachem UK Ltd, Saffron Waldron, Essex) was obtained as a dry powder, divided into $2.5 \mathrm{mg}$ aliquots in ethanol, and stored in polypropylene tubes at $-80^{\circ} \mathrm{C}$. Immediately before PAF challenge, the ethanolic PAF was dried with a stream of nitrogen and resuspended in $0.9 \%$ saline with $2.5 \mathrm{mg} / \mathrm{ml}$ human serum albumin (Immuno Ltd, Sevenoaks, Kent) to produce a concentration of $800 \mathrm{mg} /$ ml. SK\&F 104353- $Z_{2}$ and matched placebo were provided as clear phosphate buffered solutions at $\mathrm{pH} 7 \cdot 4$ for nebulisation.

\section{METHACHOLINE CHALLENGE}

Methacholine challenge was performed according to a modified Cockcroft protocol. ${ }^{24} 31$ Bronchial responsiveness was determined as the provocative concentration of methacholine causing a $35 \%$ fall in specific airways conductance $\left(\mathrm{PC}_{35} \mathrm{sGaw}\right)$ and also as the concentration causing a $30 \%$ fall in flow at $30 \%$ above residual volume from a partial expiratory flowvolume curve ${ }^{25}\left(\mathrm{PC}_{30} \mathrm{PV} \max _{30}\right)$. Measurements of sGaw were obtained by panting manoeuvres in an automated pressure-flow plethysmograph $^{26}$ (Gould 2800 autobox, Cardiokinetics Ltd, Salford) and of PV́max with a rolling seal spirometer (PK Morgan, Gillingham, Kent) attached to a differentiator (PK Morgan) and X-Y recorder (Rikadenki Mitsui Electronics UK Ltd, Chessington, Surrey). Diluent $(0.9 \%$ saline with $0.5 \%$ chlorbutol BP) was inhaled by tidal breathing from a Wright nebuliser (output $0.13 \mathrm{ml} / \mathrm{min}$ ) for two minutes, and measurements of $\mathrm{sGaw}$ (mean of eight values) and PV $\max _{30}$ (mean of two values) were obtained over the next five minutes. Doubling concentrations of methacholine were inhaled at 10 minute intervals in the same manner until the endpoint of the challenge was reached or the highest concentration of methacholine had been given. The endpoint of the challenge was defined as a fall in sGaw of at least $35 \%$ below the postdiluent value. The results were expressed as a percentage of post-diluent values. $\mathrm{PC}_{35} \mathrm{sGaw}$ and $\mathrm{PC}_{30} \mathrm{PV} \max _{30}$ were determined by linear interpolation from $\log _{10}$ dose-response curves. When $P V \max _{30}$ fell by less than $30 \%$, $\mathrm{PC}_{30} \mathrm{PV} \max _{30}$ was obtained by extrapolation provided that a definite trend in the doseresponse curve was apparent.

\section{PAF CHALLENGE}

PAF challenges were performed at a similar time of day for each subject. Baseline measurements of forced expiratory volume in one second $\left(\mathrm{FEV}_{1}\right.$, mean of three values) were obtained with a dry wedge bellows spirometer (Vitalograph Ltd, Buckinghamshire), followed by measurements of sGaw (mean of 16 values) and of PV $\max _{30}$ (mean of five values). The subject took 10 inhalations of diluent (human serum albumin $2.5 \mathrm{mg} / \mathrm{ml}$ in $0.9 \%$ saline) from a Microneb III nebuliser (Lifecare Hospital Supplies Ltd, Market Harborough, Leicester) attached to a Nebicheck dosimeter (PK Morgan) by tidal breathing while wearing a nose clip. Control measurements of sGaw were made at one minute and of $P V \max _{30}$ (mean of five values) at three minutes; venous blood was obtained for a differential white cell count at five minutes. The dosimeter was driven by air at $204 \mathrm{kPa}$ $\left(30 \mathrm{lb} / \mathrm{in}^{2}\right)$ with a flow to the nebuliser of $8 \mathrm{l} /$ min. The volume median diameter of the aerosol particles was 4-5 $\mu \mathrm{m}$, and gravimetric assessment showed the nebuliser output to be $6.4 \times 10^{-3} \mathrm{ml}$ per actuation, ${ }^{31}$ giving a predicted dose of PAF of $9.6 \times 10^{-8} \mathrm{~mol}$ per 10 inhalations.

Two millilitres of the PAF solution was placed in the nebuliser reservoir and 10 inhalations were taken as described for diluent. The ECG was monitored continuously and blood pressure measured (automatic sphygmomanometer) on completion of the inhalation. Measurements of sGaw (mean of eight values) were made at one and six minutes, and of $P V \max _{30}$ (mean of two values) at three and eight minutes. Venous blood was obtained for a white cell count at five minutes. If the maximum mean fall in sGaw was less than $35 \%$ of the control value, the challenge was repeated two weeks later with 20 inhalations of the same concentration of PAF. Subjects were excluded from further study if bronchoconstriction did not occur at the higher dose because of the potential adverse cardiovascular effects of large doses of PAF.

\section{PROTOCOL}

Bronchial responsiveness to methacholine was assessed initially (baseline), and repeated two weeks after each PAF challenges. After the bronchoconstricting dose of PAF had been determined the PAF challenge was repeated on two treatment days, at least two weeks apart, after prior inhalation of either SK\&F $104353-Z_{2}$ or placebo in a randomised, double blind, crossover study design. The methacholine challenge test was at least 24 hours before challenge with PAF, placebo, or SK\&F 104353- $Z_{2}$.

\section{TREATMENT DAYS}

Baseline pulmonary function was measured as for the PAF challenge. Three millilitres of 400 $\mu \mathrm{g} / \mathrm{ml} \mathrm{SK} \& \mathrm{~F} 104353-Z_{2}$ or placebo was placed in the reservoir of a "Pulmo-Sonic" ultrasonic nebuliser (DeVilbiss Company, Somerset, Pennsylvania). The subject inhaled the aerosol by tidal breathing, wearing a nose clip, for 10 minutes and pulmonary function measurements were repeated. Drug delivery was estimated volumetrically. PAF challenge was performed 15 minutes after the inhalation was completed with the bronchoconstricting dose of PAF previously determined for each subject. 


\section{STATISTICAL ANALYSIS}

When a $\mathrm{PC}_{30} \mathrm{PV} \max _{30}$ could not be extrapolated (eight out of 32 methacholine challenges) the points were entered into the analysis of variance as missing data (Minitab software handbook).

The coefficient of variation (SD as a percentage of the mean) for each subject was calculated for baseline values of sGaw, $P \max _{30}$, and $\mathrm{FEV}_{1}$ obtained before each methacholine and PAF challenge, and at the beginning of each treatment day. The lowest mean sGaw and PV $\max _{30}$ values after inhalation of PAF and the circulating neutrophil count at five minutes were expressed as percentages of the control post-diluent values. The effect of SK\&F $104353-Z_{2}$ and placebo on pulmonary function was assessed by comparing the changes in $\mathrm{FEV}_{1}$, sGaw, and $\mathrm{PV} \max _{30}$ after treatment by paired $t$ tests. Mean differences and 95\% confidencelimits $(95 \% \mathrm{CL})$ for the mean differences are given.

The reproducibility of the PAF challenge was assessed by comparing the greatest mean change in sGaw, $P \operatorname{Pmax}_{30}$, and neutrophil count after PAF challenges on dose finding and placebo treatment days, and expressed as the mean difference and coefficient of repeatability for each measurement. The coefficient of repeatability was calculated from the formula

$$
2 x \sqrt{\frac{\sum\left(D_{1}-D_{2}\right)^{2}}{n}},
$$

where $D_{1}$ and $D_{2}$ are the maximum mean reductions obtained after the first and second challenge and $n$ is the number of subjects. This defines $95 \%$ of the differences between the two challenges, and is the coefficient of repeatability adopted by the British Standards Institution. ${ }^{27}$ PC values were log transformed for the analysis. Changes in PC values two weeks after each PAF challenge were compared with baseline values by paired $t$ tests and by a one way analysis of variance. All data were analysed by means of the Minitab statistical package (Minitab Inc, State College, Pennsylvania). ${ }^{28}$

\section{Results}

BASELINE PULMONARY FUNCTION

The mean (range) coefficients of variation for baseline values were: $\mathrm{FEV}_{1} 3 \cdot 76 \%(2 \cdot 3-5 \cdot 8 \%)$, sGaw $9 \cdot 6 \%(4 \cdot 3-14.4 \%)$, and $8.9 \% \quad(6 \cdot 0$ $20.3 \%$ ) for $P \operatorname{Pmax}_{30}$. These are similar to previously published values. ${ }^{29} 30$

PAF CHALLENGE AND TREATMENT DAYS

PAF challenge was well tolerated with no

Table 1 Mean (SD) values of $F E V_{1}$, partial flow at $30 \%$ of vital capacity $\left(P V \max _{30}\right)$, and specific airways conductance (sGaw) before and immediately after inhalation of $S K \mathcal{E}^{\circ} F 104353-Z_{2}$ or placebo

\begin{tabular}{|c|c|c|c|c|}
\hline & \multicolumn{2}{|l|}{ Pretreatment } & \multicolumn{2}{|l|}{ Post-treatment } \\
\hline & $S K \mathcal{F} F$ 104353-Z & Placebo & $S K \mathcal{L} F 104353-Z_{2}$ & Placebo \\
\hline $\begin{array}{l}\mathrm{FEV}_{1}(\mathrm{l}) \\
\mathrm{PV} \max _{30}\left(1 \mathrm{~s}^{-1}\right) \\
\mathrm{sGaw}\left(\mathrm{s}^{-1} \mathrm{kPa}\right)\end{array}$ & $\begin{array}{l}4.54(0.75) \\
3.22(0.85) \\
3.40(0.50)\end{array}$ & $\begin{array}{l}4.44(0.69) \\
3.30(0.84) \\
3.26(0.65)\end{array}$ & $\begin{array}{l}4.46(0.71) \\
3.06(0.92) \\
3.48(0.53)\end{array}$ & $\begin{array}{l}4.42(0.70) \\
3.09(0.91) \\
3.59(0.78)\end{array}$ \\
\hline
\end{tabular}

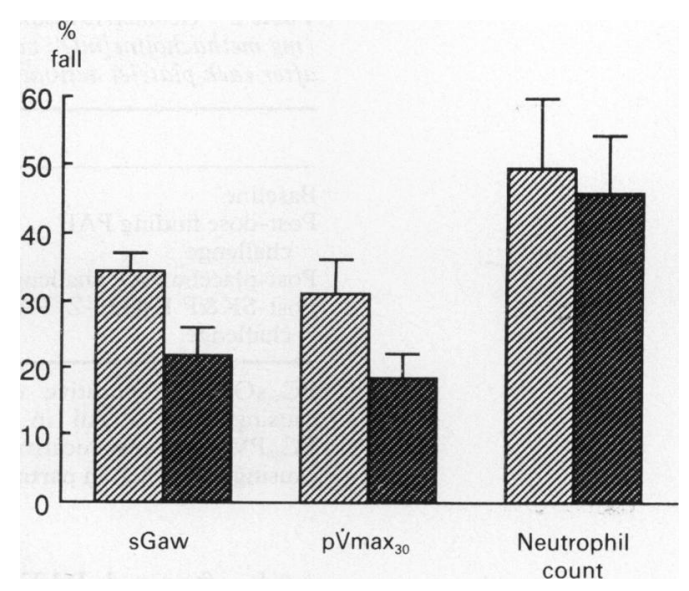

Mean PAF induced falls in specific airways conductance (sGaw), partial flow at $30 \%$ of vital capacity (PV $\left.\max _{30}\right)$, and circulating neutrophil count after inhalation of

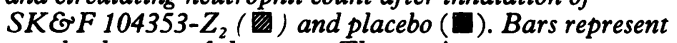
standard errors of the mean. The $y$ axis represents percentage fall from control values obtained after the inhalation of diluent.

serious side effects. Four subjects needed 10 inhalations of PAF and four 20 inhalations to produce the required fall in sGaw. All subjects experienced transient irritation of the throat, facial flushing, and a desire to cough. The maximum mean fall in sGaw and $P \dot{V} \max _{30}$ always occurred one and three minutes respectively after PAF inhalation. No changes in heart rate, blood pressure, or cardiac rhythm were observed.

No symptoms were reported by any subject after inhalation of either SK\&F 104353- $Z_{2}$ or placebo. The mean volume of solution nebulised was $1.7 \mathrm{ml}$ (SD 0.40 , range $1.2-2.6 \mathrm{ml}$ ), equivalent to 680 (range $480-1040$ ) $\mu \mathrm{g}$ of $S K \& F \quad 104353-Z_{2}$. There were no significant changes in pulmonary function after SK\&F $104353-Z_{2}$ or placebo (table 1 ).

There was a fall in sGaw, PV́max mand $_{30}$ and circulating neutrophil count after PAF challenges on the two treatment days (figure). The maximum fall after SK\&F 104353-Z $Z_{2}$ was less than that seen after placebo for sGaw $(22 \% v$ $34 \%)$ and $P V \max _{30}(19 \%$ v $31 \%)$. The mean \% difference in the fall in sGaw on the two treatment days was 12.6 (95\% CL 23.8, 1.4), $\mathrm{p}<0.05$, and for $\mathrm{PVmax}_{30}$ was $12.5(95 \% \mathrm{CL}$ $20 \cdot 8,4.2), p<0.01$. The mean difference in the PAF induced \% fall in neutrophil count between SK\&F 104353- $Z_{2}$ and placebo was 3.5 $(46 \cdot 1 v 49 \cdot 6,95 \% \mathrm{CL}-13 \cdot 6,6 \cdot 6), \mathrm{p}>0 \cdot 1$.

PAF challenge resulted in similar reductions in sGaw, $P \max _{30}$, and circulating neutrophil count on dose finding and placebo treatment days (mean difference (coefficient of repeatability) in the maximum \% fall on the two days: sGaw 6 (25), $P \dot{V} \max _{30} 3$ (36), neutrophil count $9 \%(33))$.

\section{METHACHOLINE RESPONSIVENES}

Bronchial responsiveness to methacholine two weeks after each PAF challenge did not change by more than one doubling concentration of methacholine from baseline values in any subject. There was a trend for $\mathrm{PC}_{35} \mathrm{sGaw}$ and

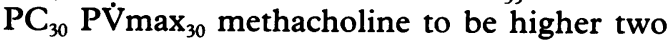


Table 2 Geometric mean $P_{35}$ Gaw and $P C_{30} P V \max _{30}$ ( $m g$ methacholine $/ \mathrm{ml}$ ): values at baseline and two weeks after each platelet activating factor (PAF) challenge

\begin{tabular}{llc}
\hline & $P C_{35}$ sGaw & $P C_{30} P \operatorname{Vmax}_{30}$ \\
\hline Baseline & $7 \cdot 2$ & $7 \cdot 5$ \\
$\begin{array}{l}\text { Post-dose finding PAF } \\
\text { challenge }\end{array}$ & $10 \cdot 2$ & $12 \cdot 2$ \\
$\begin{array}{l}\text { Post-placebo PAF challenge } \\
\text { Post-SK\&F 104353-Z PAF }\end{array}$ & $12 \cdot 7$ & $8 \cdot 6$ \\
$\quad$ challenge & $14 \cdot 1$ & $13 \cdot 4$ \\
\hline
\end{tabular}

$\mathrm{PC}_{35} \mathrm{sGaw}$-provocative concentration of methacholine causing a $35 \%$ fall in specific airways conductance; $\mathrm{PC}_{30} \mathrm{PV} \max _{30}$ - provocative concentration of methacholine causing a $30 \%$ fall in partial flow at $30 \%$ of vital capacity.

weeks after each PAF challenge than at baseline (table 2), but this was not significant (one way analysis of variance: for $\mathrm{PC}_{35} \mathrm{sGaw} \mathrm{F}=1 \cdot 25$, $\mathrm{p}=0.31$, and for $\mathrm{PC}_{30} \mathrm{PVmax} \max _{30} \mathrm{~F}=0.55$, $\mathrm{p}=0.65)$.

\section{Discussion}

In this study in normal subjects treatment with SK\&F $104353-Z_{2}$, a structural analogue of leukotriene $\mathrm{D}_{4}$, reduced the $\mathrm{C}-18 \mathrm{PAF}$ induced falls in both sGaw and PV $\max _{30}$ by $30 \%$. The effect of SK\&F $104353-Z_{2}$ on the response to PAF has not been investigated in human tissue in vitro, but the compound has no activity as a PAF antagonist in animal studies, ${ }^{23}$ and appears to be an extremely selective cysteinyl leukotriene receptor antagonist. ${ }^{223}$ Our findings suggest therefore that at least a proportion of PAF induced bronchoconstriction in man is dependent on the secondary production of cysteinyl leukotrienes. The absence of any reduction in the PAF induced fall in circulating neutrophil count suggests that the effects of PAF on circulating neutrophils occurs through a different mechanism.

The single dose PAF challenge used in this study was well tolerated, and resulted in more reproducible acute changes in pulmonary function and circulating neutrophil count than did a previous cumulative dose-response challenge. ${ }^{31}$ This may be because a single dose challenge avoids the problem of tachyphylaxis encountered with repeated doses of PAF over a short period. ${ }^{931}$

Treatment with $800 \mu \mathrm{g}$ of SK\&F 104353-Z 15 minutes before a single inhalation of leukotriene $\mathrm{D}_{4}$ reduced the mean fall in sGaw by $75 \%$ (from $55 \%$ to $14.3 \%$ ) in normal subjects. ${ }^{21}$ Our results suggest that SK\&F 104353$Z_{2}$ also antagonises the effects of endogenous cysteinyl leukotriene production in man. Whether SK\&F $104353-Z_{2}$ is an equipotent antagonist of endogenous cysteinyl-leukotrienes and exogenous inhaled leukotrienes is unknown, so we are unable to estimate the proportion of PAF induced bronchoconstriction that is related to secondary cysteinyl leukotriene production.

The transient fall in circulating neutrophils observed after inhaled PAF is due to temporary sequestration of these cells within the pulmonary circulation. ${ }^{32}$ Cysteinyl leukotrienes have no known chemotactic properties in man, so it is not surprising that pretreatment with SK\&F $104353-Z_{2}$ did not affect this response. This effect could, however, be due to secondary generation of leukotriene $B_{4}, a$ potent chemotactic agent for the human neutrophil and known to be produced in close association with PAF. ${ }^{33}$ Alternatively, this phenomenon could be due to a direct effect of PAF, mediated via specific PAF receptors on human neutrophils. $^{34}$

This study did not examine the possibility that bronchial responsiveness was increased at an earlier time after inhaled PAF because, in a previous study, ${ }^{31}$ we were unable to find any significant increase in bronchial responsiveness at any time after PAF inhalation. Bronchial responsiveness was measured two weeks after each PAF challenge in the present study to ensure that baseline responsiveness was unchanged before the next treatment day. No changes in bronchial responsiveness were found at this time, in agreement with our previous findings and those of other workers, who had used various doses of PAF. ${ }^{35-37}$ The doses of PAF used in our study $\left(9.6 \times 10^{-8} \mathrm{~mol}\right.$ or $1.9 \times 10^{-7} \mathrm{~mol}$ ) are similar to the geometric mean dose $\left(1.1 \times 10^{-7} \mathrm{~mol}\right)$ used in the study in which increased bronchial responsiveness occurred for up to four weeks after PAF inhalation in normal subjects. ${ }^{9}$ There must now be some doubt that such a prolonged increase in bronchial responsiveness is a reproducible consequence of PAF inhalation in normal subjects.

The mode of action of PAF in man has not been completely determined. Indirect mechanisms may be important, as shown by the finding that PAF induced contraction of human bronchial smooth muscle is platelet dependent in vitro, ${ }^{38}$ and that pretreatment with an antihistamine reduces PAF induced bronchospasm in vivo. ${ }^{39}$ High affinity binding sites, which may represent specific PAF receptors, have been described in human lung homogenates. ${ }^{40}$ Binding of PAF to these receptors may trigger complex intracellular transduction mechanisms that include activation of $G$ proteins and protein kinase $C$, increased turnover of inositol phosphates, and a rise in intracellular $\mathrm{Ca}^{2+}$. Phospholipase $\mathrm{A}_{2}$ may then be activated, releasing arachidonate from membrane phospholipids with the subsequent production of a cascade of mediators, including leukotrienes, prostaglandins, and thromboxane. ${ }^{41}$ The relative contributions of these different mediators in producing the biological effects attributed to PAF have yet to be determined.

Whether the metabolic pathways mediating interactions between PAF and leukotrienes are similar in normal and asthmatic subjects has not been determined, and any extrapolations from our study of inhaled PAF in normal subjects to the presumed effects of endogenous PAF in asthma must be cautious. Potent and selective PAF antagonists, 5-lipoxygenase inhibitors, and leukotriene receptor antagonists are becoming available for clinical trials; studies with these compounds will help to determine the relative importance of PAF and leukotrienes, and of interactions between them, in the pathophysiology of asthma. 
DAS was funded by the Joint Research Trust of King's College Hospital. This study was funded by a grant from Smith, Kline, and French Research Laboratories.

1 Barnes PJ, Chung KF, Page CP. Inflammatory mediators and asthma. Pharmacol Rev 1988;40:49-84.

2 Fuller RW, Dixon CMS, Dollery CT, Barnes PJ. Prostaglandin $D_{2}$ potentiates airway responsiveness to histamine and methacholine. Am Rev Respir Dis 1986;133:252-4.

3 Barnes N, Watson A, Koulouris N, Piper PJ, Costello JF Effect of preinhalation of leukotriene $\mathrm{D}_{4}$ on sensitivity to inhaled prostaglandin $F_{2 x}$ [abstract]. Thorax 1984;39:697.

4 Phillips GD, Holgate ST. Interaction of inhaled $\mathrm{LTC}_{4}$ with histamine and $\mathrm{PGD}_{2}$ on airway calibre in asthma. $J A p p$ Physiol 1989;66:304-12.

5 Chung KF, Aizawa H, Leikauf GD, Ueki IF, Evans TW, Nadel JA. Airway hyperresponsiveness induced by platelet-activating factor: role of thromboxane generation. J Pharmacol Exp Ther 1986;236:580-4.

6 Piper PJ. Formation and actions of leukotrienes. Physiol Rev 1984;64:744-61.

7 Drazen JM, Austen KF. Leukotrienes and airway responses. Am Rev Respir Dis 1987;136:985-98.

8 Barnes PJ, Chung KF. Platelet-activating factor as a mediator of allergic disease. J Allergy Clin Immunol 1988; 81:919-34.

9 Cuss FM, Dixon CMS, Barnes PJ. Effects of inhaled platele activating factor on pulmonary function and bronchial responsiveness in man. Lancet 1986;ii:189-92.

10 Rubin AE, Smith LJ, Patterson R. The bronchoconstrictor properties of platelet-activating factor in humans. $\mathrm{Am} \mathrm{Rev}$ Respir Dis 1987;136:1145-51.

11 Weiss JW, Drazen JM, McFadden ER, et al. Airway constriction in normal humans produced by inhalation of leukotriene D. JAMA 1983;249:2814-7.

12 Arm JP, Spur BW, Lee TH. The effects of leukotriene $E_{4}$ on the airway responsiveness to histamine in normal subjects with asthma and normal subjects. J Allergy Clin Immunol 1988;82:654-60.

13 Bruynzeel PLB, Koenderman L, Kok PTM, Hameling ML, Verhagen J. Platelet-activating factor (PAF-acether) induced leukotriene $\mathrm{C}_{4}$ formation and luminol dependen chemiluminescence by human eosinophils. Pharmacol Res Commun 1986;18(suppl):61-9.

14 Goswami SK, Ohashi M, Panagiotis S, Marom Z. Platelet activating factor enhances mucus glycoprotein release from human airways in vitro [abstract]. Am Rev Respir Dis 1987;136:A159.

15 Voelkel NF, Worthen S, Reeves JT, Henson PM, Murphy RC. Nonimmunological production of leukotrienes induced by platelet-activating factor. Science 1982;218: 286-8.

16 Bonnet J, Thibaudeau D, Bessin P. Dependency of the PAFacether induced bronchospasm on the lipoxygenase pathway in the guinea-pig. Prostaglandins 1983;26:457-66.

17 Cammussi G, Montrucchio G, Antro C, Bussolino F, Tetta C, Emanuelli G. Platelet-activating factor-mediated contraction of rabbit lung strips: pharmacologic modulation Immunopharmacology 1983;6:87-96.

18 Jancar S, Theriault P, Lauziere $M$, Braquet $P$, Sirois $P$. PAF-induced release of spasmogens from guinea-pig lungs. Br J Pharmacol 1989;96:153-62.

19 Stimler NP, O'Flaherty JT. Spasmogenic properties of platelet-activating factor: evidence for a direct mechanism in the contractile response of pulmonary tissues. $\mathrm{Am} \mathrm{J}$ Pathol 1983;113:75-84.

20 Fitzgerald MF, Payne AN, Garland LG, Whittle BJR. Failure of 5-lipoxygenase inhibition with BW A4C to reduce bronchoconstriction induced by inhaled plateletactivating factor [abstract]. Am Rev Respir Dis 1988; 137:A28.
21 Evans JM, Barnes NC, Piper PJ, Costello JF. Dose-related cysteinyl-leukotriene antagonism by an inhaled analogue of leukotriene $\mathrm{D}_{4}, \mathrm{SK} \& \mathrm{~F} 104353-\mathrm{Z}_{2}$, in man [abstract] Am Rev Respir Dis 1989;139:A329.

22 Evans JM, Barnes NC, Zakrzewski JT, Glenny HP, Piper PJ, Costello JF. Effects of an inhaled leukotriene (LT) antagonist, SK\&F $104353-Z_{2}$, on $\mathrm{LTD}_{4}$ and histamine induced bronchospasm in normal man [abstract]. $\mathrm{Br}$ Clin Pharmacol 1988;26:677P-8P.

23 Hay DWP, Muccitelli RM, Tucker SS, et al. Pharmacologic profile of SK\&F 104353: a novel, potent and selective peptidoleukotriene receptor antagonist in guinea pig and human airways. J Pharmacol Exp Ther 1987;243:474-81.

24 Cockcroft DW, Berscheid BA. Measurement of responsiveness to inhaled histamine: comparison of $F_{12}$ and $s G a w$ Ann Allergy 1983;51:374-7.

25 Bouhuys A, Hunt VR, Kim BM, Zapletal A. Maximum expiratory flow rates in induced bronchoconstriction in man. J Clin Invest 1969;48:1159-68.

26 Dubois AB, Botelho SY, Comroe JH. A new method for measuring airway resistance in man using a body plethysmograph: values in normal subjects and in patients with respiratory disease. J Clin Invest 1956;35:327-35.

27 Bland J, Altman DG. Statistical methods for assessing agreement between two methods of clinical measurement. Lancet 1986; i:307-10.

28 Ryan BF, Joiner BL, Ryan TA. Minitab handbook. 2nd ed. Boston, Mass: PWS-Kent, 1976.

29 Larsson K, Hedenstrom H, Malberg P. Learning effects, variation during office hours and reproducibility of static and dynamic spirometry. Respiration 1987;51:214-22.

30 Tattersfield AE, Keeping IM. Assessing change in airway calibre-measurement of airway resistance. $\mathrm{Br} J$ Clin Pharmacol 1979;8:307-19.

31 Spencer DA, Green SE, Evans JM, Piper PJ, Costello JF. Platelet-activating factor does not cause a reproducible increase in bronchial responsiveness in normal man. Clin Exp Allergy 1990;20:525-32.

32 Tam FWK, Clague J, Dixon CMS, et al. Neutrophil sequestration in normal human lung after inhalation of platelet activating factor (PAF). Thorax 1990;10:791.

33 Sisson JH, Prescott SM, McIntytre TM, Zimmerman GA Production of platelet-activating factor by stimulated human polymorphonuclear leukocytes. J Immunol 1987; 138:3918-26.

34 Dent G, Ukena D, Chanez P, Sybrecht GW, Barnes PJ. Characterisation of PAF receptors on human neutrophils using the specific antagonist, WEB 2086: correlation between receptor binding sites and function. FEBS Let 1989;244:365-8.

35 Gebré-Michel I, Leuenberger P. Inhalation of $400 \mu \mathrm{g}$ of platelet activating factor (PAF) does not induce bronchial hyperreactivity (BHR) as determined by spirometric tests [abstract]. Eur Respir J 1989;2(suppl 5):302S.

36 Lai CKW, Jenkins JR, Polosa R, Holgate ST. Inhaled PAF fails to induce airway hyperresponsiveness in norma human subjects. J Appl Physiol 1990;68:919-26.

37 Stenton SC, Ward C, Duddridge $M$, et al. The actions of GR3219B, a thromboxane receptor antagonist, on PAFinduced bronchoconstriction and bronchial hyperresponsiveness. Clin Exp Allergy 1990;20:311-7.

38 Schellenberg RR, Walker B, Snyder F. Platelet-dependen contraction of human bronchus by platelet activating factor [abstract]. J Allergy Clin Immunol 1983;71:145.

39 Smith LJ, Rubin A-H E, Patterson, R. Mechanism of platelet activating factor-induced bronchoconstriction in humans. Am Rev Respir Dis 1988;137:1015-9.

40 Hwang S-B, Lam M-H, Shen TY. Specific binding sites for platelet activating factor in human lung tissues. Biochem Biophys Res Commun 1985;128:972-9.

41 O'Flaherty JT, Wykle RL. PAF and cell activation. In: Barnes PJ, Page CP, Henson PM, eds. Platelet activating factor and human disease. Oxford: Blackwell, 1989:117-37. 